\title{
Assessment of Lecturers' Perceptions of Postgraduate Students' Academic Motivation and Emotions in South-West, Nigeria
}

\section{Mayowa Olurotimi Ogunjimi}

$\mathrm{PhD}$. Department of Adult and Primary Education, Faculty of Education, University of Ilorin, Ilorin, Nigeria, ogunjimimayowa@gmail.com

\section{Banjo Moshood Lawal}

Department of Social Sciences Education, Faculty of Education, University of Ilorin, Ilorin, Nigeria, lawalbanjo@yahoo.com

\begin{abstract}
This study assessed lecturers' perceptions of postgraduate students' academic motivation and emotions in South-west, Nigeria. The researchers employed descriptive survey research design for the study. The population of the study comprised all university lecturers in South-west, Nigeria while the target population consisted of all lecturers taking postgraduate studies in Federal Universities across South-west, Nigeria. The study sample consisted of 100 respondents purposively selected from five Federal Universities (University of Lagos, University of Ibadan, Federal University of Agriculture, Abeokuta, Federal University of Technology, Akure and Obafemi Awolowo University) in South-west. Lecturers' Perception of Postgraduate Students Academic Motivation and Emotions Questionnaire of 4-point Likert type, developed by the researchers with Cronbach Alpha reliability coefficient value of 0.83 was used for data collection. The data collected were analysed using frequency, percentages and multivariate analysis of variance. The findings showed that the perceived academic motivation of postgraduate students was average and emotion towards academic activities was stable. Also, the study showed a non-significant difference in male and female lecturers' perception of postgraduate students' academic motivation and emotion. It was, therefore, recommended that academic activities at the postgraduate level should be such that will raise the motivation level and stabilize the emotion of the students.
\end{abstract}

Keywords: assessment, perception, motivation, emotion, postgraduate studies.

\section{INTRODUCTION}

Stakeholders in Nigerian education system are concerned about students' achievements and academic standard; being that success in education is highly instrumental to the technological, socio-economic and political development of a nation. For overall national development, academic achievement of students, who are leaders of tomorrow, must be harnessed. Harnessing students' academic achievement will entail identification and treatment of factors capable of manning or making good academic achievement. Such factors capable of predicting students' academic achievement include academic motivation and emotions (Muola, 2010).

Academic motivation, as one of the factors affecting academic achievement, is the enthusiastic spirit behind student's inspiration to learn and excel in academic related activities. It is the degree to which individuals are energized for attainment of academic rewards, such as good grades, praise from fellow

Citation: Ogunjimi, M.O. \& Lawal, B.M. (2020). Assessment of Lecturers' Perceptions of Postgraduate Students' Academic Motivation and Emotions in South-West, Nigeria. Anatolian Journal of Education, 5(2), 51-58. https://doi.org/10.29333/aje.2020.524a 
students and teachers, and feelings of personal mastery in academic engagements (Muola, 2010). Academic motivation is an intrinsic motive to achieve just for the sake of achieving rather than achievement in the service of some other motives. Need for achievement is one of the psychological motives that play an important role in success and achievements of a man of which teachers are not exception (Gesinde, 2000). Academic motivation, therefore, gives strength and direction to behavior and gives energy to the students, in maintaining the energy that directs their activities. Gesinde (2000) stressed that the urge to succeed academically differs from one individual to the other; as for some, the necessity for academic achievement is very high while, for others it is very low. Individuals with high intentions to achieve usually act in ways that will enable them to perform better than others; which would not have been possible if not motivated. This suggests that the place of motivation in academic success cannot be jettison because it is what gets one going, keeps one going, and determines where one is to go (Slavin, 2006). Motivation is one of the elements that contribute to academic success. It is crucial to a student's academic success at any age and any academic level. Motivation is what causes people to behave as they do. Motivation outlines the achievement and pursuit of goals which must be achieved. It is in relation to this that Deci and Ryan (2000) stressed that motivation is greatly appreciated because of the consequences it produces.

The desire for high level of academic achievement may be intrinsically or extrinsically incline since there is intrinsic motivation and extrinsic motivation. Intrinsic motivation, according to Ryan and Deci (2000), is the doing of an activity or engaging in an event for its inherent satisfactions instead of some detachable significances. Intrinsic motivation is concern with engagement in an activity for itself, and the pleasure and satisfaction derived from participation in the activity and accomplishment of certain tasks (Ayub, 2010). Individuals with intrinsic motivation have inherent locus of control and enjoy achievement of a task for pleasure, engage in activities that give rise to experience of stimulating sensations, and are eager to learn new things (Ayub, 2010). When a person enjoys a work or activity, see it as an opportunity to learn and participate without the sake of any external reward, person is motivated intrinsically (Coon \& Mitterer, 2010). Or when someone performs certain activities for internal interest and satisfaction, it refers to intrinsic motivation (Brown, 2007). Intrinsic Motivation is type of motivation in which student is motivated internally. The students who are accomplishing the task, they are intrinsically motivated students.

Contrariwise, extrinsic motivation explains the value of the performance of an activity in order to attain some separable outcome (Ryan \& Deci, 2000); in terms of a number of engagements that function as a means to an end and not an end in itself. According to Brown (2007), extrinsic motivation is the tendency to perform activities for known external rewards, whether they be tangible (like money) or psychological (like praise) in nature. Extrinsic motivation refers to behaviour that is driven by external rewards such as money, fame, grades, and praise. This type of motivation arises from outside the individual, as opposed to intrinsic motivation. It is the desire to achieve something not for the enjoyment of the thing itself, but because doing so leads to a certain result (Pintrich \& Schunk, 2002). Extrinsic motivation consists of three different components, with the first component as external regulation, which is regulated through outside rewards, punishments and constraints; introjected regulation, which concerns with the internalizing the importance of and the reasons for doing certain activities; and identified regulation, which involves choosing to identify with the values associated with academic activities (Pintrich \& Schunk, 2002). Motivation can come from the outside, such as the motivation to win medals, receive financial rewards, and attract attention from the media. This is known as external, or extrinsic, motivation because it involves participation in sport for some kind of reward that is external to the process of participation.

Some studies exist on the influence of academic motivation on students' academic achievement. For instance, Krishnamurthy (2000) found a positive and significant relationship between academic motivation and academic achievement. Also, Matuga (2009) found a positive relationship between 
academic motivation and students' academic achievement. In a related study among primary school pupils conducted by Othman and Leng (2011), on the relationship between intrinsic motivation and academic achievement, a significant correlation between intrinsic motivation and academic achievement was also reported.

Another variable capable of dictating students' academic achievement is their emotions. Students' emotion is their feelings about school, and their interest in the school activities. It comprised students' attitudes, interests, and values particularly related to positive or negative interactions with staff, students, academic community, or the institution (Fredericks \& Blumenfield, 2004). Students' emotional reactions or engagement creates ties with institutions and builds students' desire to work assiduously for success. In the opinion of Fredericks and Blumenfield (2004), emotion can be explained in terms of students' affective reactions, emotional reactions, and school identification. The affective reactions explained students' engagement in the classroom in terms of their level of interest, boredom, anxiety, sadness, and happiness. Emotional reactions are the positive or negative feelings students have toward the institution and teachers. School identification pertains to students' feelings of belonging and importance within the institutional environment (Fredericks \& Blumenfield, 2004). This suggests that students' emotional reaction or engagement is a three-dimensional construct. The three components aforementioned will determine whether a student is emotionally engaged or disengaged which will consequently dictate their academic outcome in the form of achievement. When a student is overwhelmed with feelings of boredom, sadness, and anxiety, such a student is emotionally unstable, while feelings related to school safety and connectedness with peers and staff demonstrates emotional stability and engagement (Pintrich \& Schunk, 2002).

Over the years, there has been increasing concern over postgraduate students' emotion and inspiration to learn and excel in their academic pursuit. Such concern steamed out of the common observation that many postgraduate students cannot effectively undertake research work which is the bedrock of postgraduate programme. The above observations have made the lecturers to have diverse perceptions about postgraduate students' motivation and emotional state. Lecturers taking the postgraduate students have been wondering whether the students are academically motivated and are emotionally stable to effectively undertake research work. Thus, there is a need to find out through lecturers' perception whether the students are academically motivated and whether they have positive emotion towards academic activities. This study is, therefore, designed to assess lecturers' perceptions of postgraduate students' academic motivation and emotions in South-West, Nigeria. The choice of lecturers, as against the postgraduate students, was premised on the need to avoid all forms of bias that might arise from students' self-assessment. Specifically, the study determined the:

1. Level of academic motivation of postgraduate students as perceived by lecturers;

2. Emotional state of postgraduate students in relation to their academic success perceived by lecturers; and

3. Difference in male and female lecturers' perception of postgraduate students' academic motivation and emotion.

In line with the purpose of the study, the following research questions were answered in the course of the study.

1. What is the level of academic motivation of postgraduate students as perceived by lecturers?

2. What is the emotional state of postgraduate students in relation to their academic success as perceived by lecturers? 
3. Is there any difference between male and female lecturers' perception of postgraduate students' academic motivation and emotion?

In addition to the research questions, a null hypothesis was raised as follow:

1. There is no significant difference in male and female lecturers' perception of postgraduate students' academic motivation and emotion.

\section{METHOD}

\section{Research Design}

This study employed descriptive survey research type. A descriptive research involves gathering of information for the purpose of explaining and interpreting existing conditions, prevailing practices, beliefs, disposition and on-going practice or process (Singaravelu, 2007). The goal of survey/descriptive study is to discover on-going situation or practice and to describe or explain "what happened". Descriptive design is considered appropriate for this study since it will afford the researchers opportunity of carrying out a holistic assessment of lecturers' perception of postgraduate students' achievement motivation emotion towards academic activities.

\section{Population and Sample}

The population of the study comprised all university lecturers in South-west, Nigeria while the target population consisted of all lecturers taking postgraduate studies in Federal universities across Southwest. The study sample consisted of 100 respondents that were purposively selected from five Federal universities (University of Lagos, University of Ibadan, Federal University of Agriculture, Abeokuta, Federal University of Technology, Akure and Obafemi Awolowo University) in South-west. The choice of purposive sampling premised on the fact that the research was targeted towards lecturers taking postgraduate studies, in which simple random might not be possible

\section{Instrumentation}

Lecturers' Perception of Postgraduate Students Academic Motivation and Emotions Questionnaire of 4-point Likert type, developed by the researchers was used to collect information for the study. Reliability of the instrument was determined using Cronbach Alpha method of establishing reliability. To achieve this, the instrument was administered once, outside the study area, to 40 randomly selected lecturers who have the same characteristics with the intending respondents, but are not part of the main study, and the scores obtained were analysed using Cronbach Alpha with the aid of SPSS version 23.0. The instrument has reliability yielded Cronbach Alpha coefficient of 0.83 . This provided strong basis for appropriateness of the instrument for the purpose of the study.

\section{Data Analysis}

Data obtained were analyzed using appropriate statistical tools. The research questions raised in the study were answered using descriptive statistics of frequency and percentages. The hypothesis formulated in the study was tested using multivariate analysis of variance with the use of Statistical Package for Social Sciences (SPSS). Multivariate analysis of variance (MANOVA) is used to determine whether there are any differences between independent groups on more than one continuous dependent variable. In statistics, multivariate analysis of variance (MANOVA) is a procedure for comparing multivariate sample means. As a multivariate procedure, it is used when there are two or more dependent variables, and is typically followed by significance tests involving individual dependent variables separately (Warne, 2014). The hypothesis was tested at 0.05 level of significance. 


\section{FINDINGS}

Research Question 1: What is the level of academic motivation of postgraduate students as perceived by lecturers?

To answer the research question, lecturers' perception on academic motivation of postgraduate students were summed and subjected to percentage analysis. The minimum score, maximum score and range score of the respondents were 10,40 and 30 . The range was divided by the three levels of motivation (high, average and low) and the cut off was 10. Scores between 10-20, 21-30 and 31-40 are categorized as low, average and high level of motivation respectively. The result is presented in Table 1.

Table 1

Level of Academic Motivation of Postgraduate Students as Perceived by Lecturers

\begin{tabular}{lll}
\hline Levels & Frequency & Percentage (\%) \\
\hline High & 17 & 17.0 \\
Average & 72 & 72.0 \\
Low & 11 & 11.0 \\
Total & 100 & 100.0 \\
\hline
\end{tabular}

Result in Table 1 indicated that $17(17 \%)$ of the respondents perceived that the level of academic motivation of postgraduate students was high, $72(72 \%)$ perceived that the level of academic motivation of postgraduate students was average, while $11(11 \%)$ perceived that the level of academic motivation of postgraduate students was low. This shows that the level of academic motivation of postgraduate students was average on majority as perceived by lecturers. This implies that the energetic force behind postgraduate students' desire to excel in their academic pursuits was not strong enough.

Research Question 2: What is the emotional state of postgraduate students in relation to their academic success as perceived by lecturers?

To answer the research question, lecturers' perceptions on emotional state of postgraduate students in relation to their academic were summed and subjected to percentage analysis. The minimum score, maximum score and range score of the respondents were 10,40 and 30 . The range was divided by the two levels emotional state (stable and unstable) and the cut off was 15. Scores between 10-25 and 2640 are categorized as unstable and stable emotion respectively. The result is presented in Table 2.

Table 2

Emotional State of Postgraduate Students in Relation to Their Academic Success Perceived by Lecturers

\begin{tabular}{lll}
\hline Emotional State & Frequency & Percentage $(\%)$ \\
\hline Stable & 81 & 81.0 \\
Unstable & 19 & 19.0 \\
Total & 100 & 100.0 \\
\hline
\end{tabular}

Result in Table 2 indicated that $81(81 \%)$ of the respondents perceived the emotional state of postgraduate students as stable while $19(19 \%)$ perceived that the emotional state of postgraduate students was unstable. This shows that the perceived emotional state of postgraduate students was 
stable on majority. This implies that the postgraduate students of the lecturers involved in this study had stable emotions in relation to their academic success.

Null Hypothesis: There is no significant difference in male and female lecturers' perception of postgraduate students' academic motivation and emotion

To test the null hypothesis, responses on male and female lecturers' perception of postgraduate students' academic motivation and emotion were coded and analysed using Multivariate Analysis of Variance (MANOVA). The result of the analysis is presented in Table 3.

Table 3

Multivariate Analysis of Differences in Male And Female Lecturers' Perception of Postgraduate Students' Academic Motivation and Emotion

\begin{tabular}{lllllll}
\hline Effect & & Value & F & Hypothesis df & Error df & Sig. \\
\hline \multirow{5}{*}{ Intercept } & Pillai's Trace & .973 & $3545.751^{\mathrm{b}}$ & 1.000 & 98.000 & .000 \\
& Wilks' Lambda & .027 & $3545.751^{\mathrm{b}}$ & 1.000 & 98.000 & .000 \\
& Hotelling's Trace & 36.181 & $3545.751^{\mathrm{b}}$ & 1.000 & 98.000 & .000 \\
& Roy's Largest Root & 36.181 & $3545.751^{\mathrm{b}}$ & 1.000 & 98.000 & .000 \\
\hline \multirow{5}{*}{ Gender } & Pillai's Trace & .018 & $1.789^{\mathrm{b}}$ & 1.000 & 98.000 & .184 \\
& Wilks' Lambda & .982 & $1.789^{\mathrm{b}}$ & 1.000 & 98.000 & .184 \\
& Hotelling's Trace & .018 & $1.789^{\mathrm{b}}$ & 1.000 & 98.000 & .184 \\
& Roy's Largest Root & .018 & $1.789^{\mathrm{b}}$ & 1.000 & 98.000 & .184 \\
\hline
\end{tabular}

a. Design: Intercept + Gender

b. Exact statistic

Result in Table 3 shows that there is no significant difference in male and female lecturers' perception of postgraduate students' academic motivation and emotion. This is evident with the F-calculated value of 1.789 and p-value of 0.184 which is greater than 0.05 level of significance $(0.184>0.05)$. Since the p-value is greater than 0.05 level of significance, the null hypothesis which states that there is no significant difference in male and female lecturers' perception of postgraduate students' academic motivation and emotion is not rejected.

\section{DISCUSSION}

This study found that the level of academic motivation of postgraduate students was average on majority as perceived by lecturers. This means that majority of the sampled respondents expressed average level of academic motivation on postgraduate students. This result is possible where all the lecturers sampled for the study have the same experience and opinion about their postgraduate students. This result is in line with opinion of Gesinde (2000) that the urge to succeed academically differs from one individual to the other; as for some, the necessity for academic achievement is very high while, for others it is very low. Individuals with high intentions to achieve usually act in ways that will enable them to perform better than others. This suggests that the place of motivation in academic success cannot be jettison because it is what gets one going, keeps one going, and determines where one is to go. Postgraduate students' intention to succeed academically was perceived and expressed as been average by their lecturers.

This study also confirmed that the perceived emotional state of postgraduate students was stable on majority. This means that emotional state of postgraduate students is stable on majority as expressed by their lecturers. This result is plausible where the lecturers have critically examined the students and viewed their ability to control and manage their emotions in diverse circumstances as pleasing. It is 
only in such condition that the students' emotional state can be adjudged stabled. This result corroborates the earlier work of Singaravelu (2007) who found that the emotion of student teachers in Pondicherry region of Urdu was found to be above average as the mean and standard deviation were found to be 33.46 and 9.46, respectively. Students' emotional state will be adjudged stable if they exhibit feelings related to school safety and connectedness with peers and staff demonstrates emotional stability and engagement. Students' emotional reactions or engagement creates ties with institutions and builds students' desire to work assiduously for success. Students' emotional state determines whether a student is emotionally engaged or disengaged which will consequently dictate their academic outcome in the form of achievement.

The result of this study showed that there is no significant difference in male and female lecturers' perception of postgraduate students' academic motivation and emotion. This implies that lecturers' perception of postgraduate students' academic motivation and emotion is independent of gender. Both male and female lecturers taking postgraduate students have the same level of perception/opinion of postgraduate students' academic motivation and emotion. This result is possible where the lecturers are objective in their perception of the postgraduate students' motivation and emotion towards academic pursuits. The result is also possible where both male and female lecturers' observation of the students' academic motivation commensurate their emotional engagement in the school community. This is on the notion raised by Fredericks and Blumenfield (2014) that motivation and emotion can be explained in terms of students' level of engagement, affective reactions, emotional reactions, and school identification; which are the attributes perceived by the respondents sampled for this study.

\section{CONCLUSION}

This place of academic motivation and emotional stability cannot be jettisoned if students, especially at the postgraduate level, must excel in their academic pursuits. The need to unveil the degree of energetic force behind postgraduate students' desire to excel in their academic pursuits and to understand the emotional state of the students in relation to their academic success necessitated this study which aimed at assessing lecturers' perceptions of postgraduate students' academic motivation and emotions in South-west, Nigeria. Based on the findings of the study, it is, therefore, concluded that the energetic force behind postgraduate students' desire to excel in their academic pursuits was not strong enough. This is premised on the level of academic motivation of postgraduate students that was assessed to be average by lecturers. It can as well be concluded that the postgraduate students in South-west have high level of emotional intelligence to have been adjudged emotionally stable. This is premised on the outcome of the study that emotional state of postgraduate students is stable on majority as expressed by their lecturers. The study, on the final note, concluded that lecturers' perception of postgraduate students' academic motivation and emotion is independent of gender.

\section{SUGGESTIONS}

Based on the findings, it was suggested that academic activities at the postgraduate level should be such that will raise the motivation level and stabilize the emotion of the students; lecturers should continue to be critical and objective in their perception towards issues. This will enable them to always give objective and unbiased judgment about critical issues relating students' emotion; lecturers can make positive impact in their students' academic motivation and emotion by designing learning and instructions such that will foster interest, and positively activate the students' emotion; and that postgraduate programme should be designed to enhance the pursuit of autonomous educational goals and facilitate students' experience of subjective value of the activities that makes up the programme. 


\section{REFERENCES}

Ayub, N. 2010.Effect of intrinsic and extrinsic motivation on academic performance. Pakistan Business Review, 363-372.

Babbie, E. R. (2009). The Practice of Social Research (12th ed.). Wadsworth. pp. 436-440.

Brown, L. V. (2007). Psychology of motivation. New York: Nova Science Publishers.

Coon, D. \& Mitterer, J. O. (2010). Introduction to psychology: Gateways to mind and behavior with concept maps. Belmont, CA: Wadsworth.

Fredricks, J. A., Blumenfeld, P. C., \& Paris, A. H. 2004. School engagement: Potential of the concept, state of the evidence. Review of Educational Research, 74(1), 59-109.

Gesinde, A.M. (2000) Motivation. In Z.A.A. Omideyi (editor) Fundamental of Guidance and Goodwin, B. \& Miller, K. (2013). Grit talent student success. Educational Leadership, 2: 74-76.

Krishnamurthy, S. 2000. Achievement as Related to Academic Achievement Motivation and Attitude towards Study of History. The Education Review, 106, 95- 98.

Latham, G. (2011). Work Motivation: History, Theory, Research and Practice. NJ, SAGE.

Matuga, J. M. 2009. Self-Regulation, Goal Orientation, and Academic Achievement of Secondary Students in Online University Courses. Educational Technology \& Society, 12 (3), 4-11.

Muola, J. M. 2010. A Study of the Relationship between Academic Achievement Motivation and Home Environment among Standard Eight Pupils. Educational Research and Reviews, 5(5), 213-217.

Othman, N., \& Leng, B. K. 2011. The Relationship between Self-Concept, Intrinsic Motivation,SelfDetermination and Academic Achievement among Chinese Primary School Students. International Journal of Psychological Studies,3(1), 233-241.

Pintrich, P. R. \& Schunk, D. H. 2002. Motivation in education: Theory, research, and applications (2nd ed.). Upper Saddle River, N.J.: Merrill.

Ryan, R. \& Deci, E. 2000. Intrinsic and extrinsic motivations: Classic definitions and new directions. Contemporary Educational Psychology, 25(1), 54-67.

Singaravelu S. 2007. Emotional Intelligence of student teachers (pre-service) at primary level in Puducherry region. M.Ed. Dissertation.

Slavin, D. 2006. The Educational Psychology: Theory into Practice. Eaglewood Cliff, N. J.: Prentice Hall.

Warne, R. T. (2014). A primer on multivariate analysis of variance (MANOVA) for behavioral scientists. Practical Assessment, Research \& Evaluation. 19 (17): 1-10. 